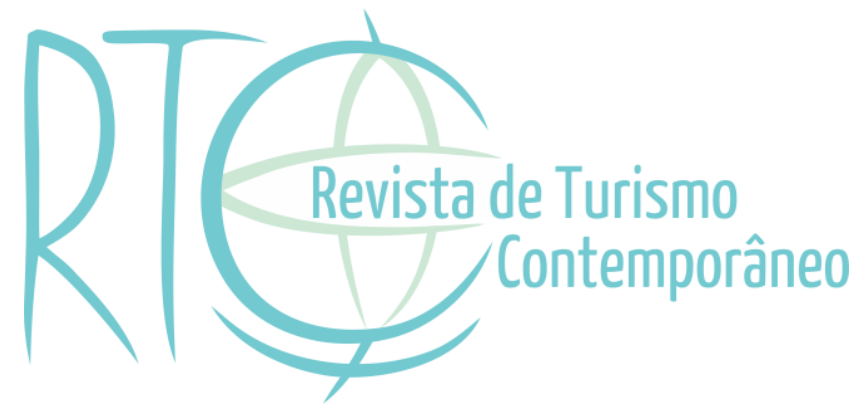

\title{
Turismo, mineração e desenvolvimento: relações complexas
}

\section{Tourism, mining and development: complex relationships}

\section{Diomira M.C.P. Faria}

Profa. Adjunta do Curso de Turismo -da Universidade Federal de Minas Gerais-UFMG, Belo Horizonte/ MG, Brasil.

E-mail: diomira@uol.com.br

\section{Jorge Fernandes de Freitas Neto}

Graduando do Curso de Turismo, bolsista voluntário de Iniciação Científica, da Universidade Federal de Minas Gerais-UFMG, Belo Horizonte /MG, Brasil.

E-mail: madruga4x4@gmail.com

Jordana Romano Ferreira

Graduanda do Curso de Turismo, Bolsista CNPQ, Universidade Federal de Minas GeraisUFMG, Belo Horizonte/MG, Brasil.

E-mail: jordana.romano@hotmail.com 


\title{
RESUMO
}

Diante de um cenário onde duas atividades fazem uso dos recursos naturais de um território buscando se estabelecer através da premissa de contribuir para o seu desenvolvimento, surgiu a necessidade de analisar os diversos impactos econômicos e sociais causados pela atividade turística e de extração mineral, no município de Conceição do Mato Dentro - MG. De caráter exploratório, utilizando-se de dados secundários e de entrevistas com lideranças locais, os resultados do estudo mostraram que a mineração foi determinante para a expansão dos empregos e aumento do PIB municipal, embora seja responsável por danos sociais e ambientais. Cenários de longo prazo conferem ao turismo maior vantagem relativa comparado à mineração.

Palavras-chave: Turismo. Mineração. Desenvolvimento. Impacto. Conceição do Mato Dentro.

\begin{abstract}
Faced with a scenario where two activities have used natural resources from a specific territory, seeking to establish itself through the premise of contributing to their development, it became necessary to analyze the economic and social impacts caused by tourism and mining in the municipality of Conceição do Mato Dentro - MG, Brazil. This exploratory research relies on secondary data and qualitative approach such as interviews with local leaders. The results showed that mining was crucial to job expansion and the increase of the municipal GDP, although it is responsible for social and environmental damage. Long-term scenarios give larger tourism relative advantage when compared to mining.
\end{abstract}

Keywords: Mining. Devolopment. Impacts. Conceição do Mato Dentro. 


\section{INTRODUÇÃO}

Diante de um cenário onde duas atividades que fazem uso dos recursos naturais de um determinado território buscam se estabelecer através da premissa de contribuir para o desenvolvimento, surge a necessidade de analisar os diversos impactos causados tanto pela atividade turística quanto pela extração mineral no município de Conceição do Mato Dentro, no estado de Minas Gerais.

Figura 1- Localização do município de Conceição do Mato Dentro, na porção central do Estado, na região denominada Médio Espinhaço.

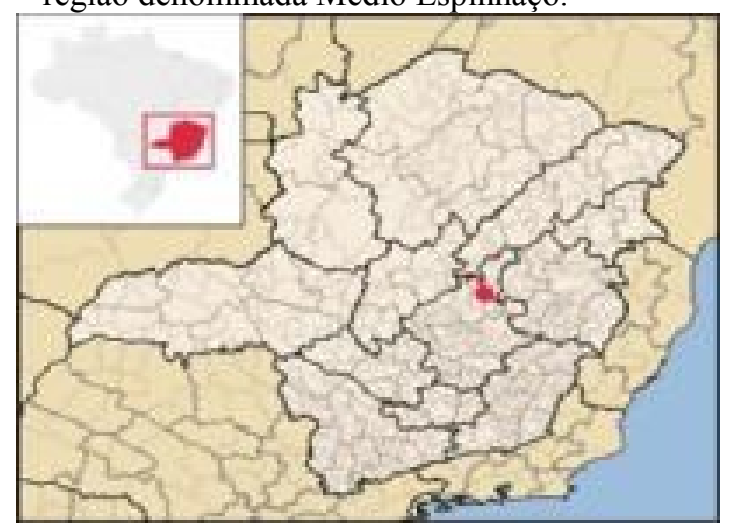

Fonte: Google (2016)

Conceição do Mato Dentro surge na segunda metade do século XVI, onde as investidas aos sertões vão ganhando força por parte dos colonizadores portugueses que buscavam as riquezas de Sabarabuçu, na língua indígena, a serra que brilha (Costa, 2009). No século XVIII vários eram os caminhos que levavam às Minas Gerais, porém já existiam muitos "descaminhos" por onde o ouro e o diamante podiam circular longe das vistas da Coroa Portuguesa. Portugal exige, através da Ordem Régia, que a circulação aconteça apenas por algumas trilhas e estradas que então receberam a designação de Estrada Real (Costa, 2009). Estrategicamente localizada na porção norte desta via de escoamento de ouro e principalmente de diamantes, que ligava Vila Rica (atual Ouro Preto) ao Distrito Diamantino (atual Diamantina), a vila de Conceição se transforma em um pequeno centro urbano, no período em que a grande atividade econômica era a extração mineral no interior do país e seu escoamento para a metrópole portuguesa (Becker, 2009), daí sua herança minerária. 
O ciclo do ouro teve seu auge entre 1733 e 1748 e a partir de 1789 chega à exaustão (Mota \& Braick, 2002). De acordo com Becker (2009, p.245) “declinado o período aurífero, foi a economia de subsistência e o comércio incipiente que permitiram aos habitantes da vila de Conceição prosseguirem com sua rotina de vida." Além da tradição da agricultura familiar e do comércio, outro aspecto deixou fortes marcas na história e consolidação do território: a religião, marcada pela fé e devoção dos primeiros portugueses que ali chegaram, tornando-se um local de peregrinação e oração (Becker, 2009) ${ }^{1}$.

As atividades de subsistência dominaram a economia local por mais de dois séculos. No final da década de noventa (1990), o município busca por novas alternativas, sendo o turismo eleito como prioridade pela sociedade local. Contudo, os preços altos do minério de ferro no cenário internacional, no início dos anos 2000, causaram a reativação do setor minerário, novos projetos são desenvolvidos e o município de Conceição do Mato Dentro, com uma população estimada de 18.198 habitantes para o ano de 2015, segundo o Instituto Brasileiro de Geografia e estatística [IBGE], torna-se alvo de um grande projeto minerário.

O objetivo do presente estudo consiste em identificar a contribuição das atividades de turismo e mineração ao desenvolvimento econômico e humano do município de Conceição do Mato Dentro, através da análise dos impactos econômicos e sociais decorrentes das duas atividades.

O estudo, de caráter exploratório, foi desenvolvido através de consulta a fontes de dados secundários, utilizando-se também de entrevistas com lideranças locais, realizadas durante visitas ao município. Foi investigada a relação das atividades turísticas e de extração mineral com o território, a dinâmica econômica local, a distribuição de renda e identificados os conflitos gerados devido aos diferentes usos dados aos recursos naturais. ${ }^{1}$ Desde 1787, se estabeleceu em Conceição do Mato Dentro, no mês de junho, a festa do Jubileu do Bom Jesus
de Matozinhos. 


\section{SOBRE O CONCEITO DE DESENVOLVIMENTO}

Conceituar desenvolvimento é complexo devido a ambiguidade do termo, pois é empregado tanto para descrever um processo pelo qual uma sociedade se move de uma condição em direção a outra, como também é utilizado como o objetivo desse processo (Sharpley, 2000).

O debate sobre o desenvolvimento se fortalece no final da segunda guerra mundial, com o objetivo de definir propostas de ação política e social para acelerar o crescimento dos países mais atrasados (Faria, 2012). Nos anos cinquenta se preconiza que o desenvolvimento seria alcançado através do crescimento econômico, sendo o desenvolvimento a última etapa de um crescimento econômico contínuo, no qual mudanças radicais nos métodos de produção, com prioridade para a industrialização, levariam a um crescimento sustentado, que por sua vez conduziria ao aprofundamento das mudanças na economia e na sociedade (Rostow, 2010). Nesta concepção, desenvolvimento era sinônimo de crescimento econômico. Nos anos oitenta do século passado, desenvolvimento é considerado como a satisfação crescente das necessidades básicas de uma população e a redução das desigualdades sociais (Furtado, 1984, p.11).

O conceito acrescenta a dimensão ambiental a partir da publicação dos resultados da Comissão Mundial sobre Meio Ambiente e Desenvolvimento, através do "Relatório Brundtland", em 1987, que dissemina o termo desenvolvimento sustentável que associa a sustentabilidade ambiental ao conceito de desenvolvimento, entendido ainda como crescimento econômico (Faria, 2012, p.13). Fatores sociopolíticos entram no debate conceitual e as Nações Unidas declaram: "O objetivo principal do desenvolvimento é ampliar as possibilidades das pessoas". 2 O conceito de desenvolvimento humano absorveu as ideias de martya Sen (2000) que define desenvolvimento como liberdade, a expansão das liberdades que as pessoas disfrutam que envolvem a redução da pobreza, a participação cidadã e a democratização (Faria, 2012).

\footnotetext{
${ }^{2}$ Disponível em: http://hdr.undp.org/es/content/sobre-el-desarrollo-humano. Acesso em 19/2/2016. No original: "El objetivo principal del desarrollo es ampliar las opciones de las personas".
} 
Verifica-se que o conceito de desenvolvimento sofreu transformações no período de cinquenta anos, de um processo destinado a alcançar o crescimento econômico, onde a economia era o eixo principal de análise e de propostas, se transforma em uma ação rumo ao desenvolvimento humano, onde as pessoas tornam-se o centro do interesse de estudiosos e a ideia de autonomia, em particular, torna-se o objetivo fundamental do desenvolvimento (Faria, 2012).

Entretanto, ao utilizar o termo desenvolvimento, muitos autores não explicitam qual desenvolvimento estão se referindo, ou a quais aspectos: econômicos, sociais ou ambientais. Geralmente o termo ainda é abordado como sinônimo de crescimento econômico e sem detalhar que tipo de desenvolvimento e para quem, é utilizado como uma ideologia de progresso para todos.

Neste estudo serão abordadas as mudanças ocorridas nas dimensões econômica e social no município de Conceição do Mato Dentro, a partir do fortalecimento do turismo e da mineração no município, em uma tentativa de averiguar que tipo de processo de desenvolvimento está ocorrendo neste território.

\subsection{TURISMO E MINERAÇÃO EM CMD}

O turismo está inserido na sociedade capitalista contemporânea como uma importante atividade econômica e está presente na vida de grande parte dos habitantes das nações industriais que consomem o período de folga ou férias com os deslocamentos e as viagens. A curiosidade de conhecer o novo sempre esteve entre as "necessidades básicas e imediatas" (Krippendorf, 2009, p.14) do ser humano.

A partir do pressuposto que o turismo pode ser uma atividade capaz de conciliar desenvolvimento com a conservação ambiental, localidades com recursos ou atrativos de interesse turístico intensificam os esforços para entrar no rol seleto de destinos turísticos consolidados. Assim foi com o município de Conceição do Mato Dentro, por sua localização 
estratégica na região da Serra do Espinhaço e inserida no percurso da Estrada Real ${ }^{3}$, que se utiliza do antigo caminho colonial para formatação de propostas de políticas públicas no âmbito estadual, visando estabelecer e regionalizar o turismo (Becker, 2009).

No ano de 2005, concedeu-se pela UNESCO o diploma de Reserva da Biosfera à Serra do Espinhaço-RBSE, devido à biodiversidade e pelo patrimônio histórico-cultural que abriga, gerando expectativas para a população de CMD de um desenvolvimento turístico sustentável (Becker, 2009). Dentre os atrativos naturais localizados no território de Conceição do Mato Dentro está a cachoeira do Tabuleiro, localizada no distrito de Tabuleiro do Mato Dentro, que com 273 metros de queda é a terceira maior cachoeira do Brasil, conhecida também como o coração das águas do Espinhaço. Também estão presentes no município diversos outros atrativos naturais ligados a formação geológica da região. Existem ainda os atrativos culturais que estão ligados a religião, como o bicentenário Jubileu do Bom Jesus do Matozinhos e o vilarejo de Cemitério do Peixe.

Os atores do território percebem sua vocação turística e de acordo com Becker (2009) "as elites regionais do poder" elegem a atividade turística como capaz de levar o desenvolvimento econômico para a região. O poder público e o empresariado local abraçam a ideia e várias ações, durante a década de noventa e início dos anos 2000, passam a ser realizadas visando a capacitação da mão de obra e implantação de infraestrutura turística, apostando no turismo como um vetor de desenvolvimento apoiado no segmento de ecoturismo. A cidade chega a se intitular "capital mineira do ecoturismo".

No ano de 2006 surge a possibilidade (que se concretiza anos depois) de extrair minério de ferro em escala industrial em uma porção da borda leste da Serra do Espinhaço, na região que abrange os municípios de Conceição do Manto Dentro, Serro, Alvorada de Minas e Dom Joaquim. O empreendimento, intitulado Minas Rio, é apresentado como grande oportunidade de desenvolvimento para a região. Inicialmente ligado a MMX-Minas Rio Mineração e Logística Ltda, hoje se encontra nas mãos da empresa Anglo American.

O projeto prevê a implantação de três estruturas associadas: um mineroduto que liga a mina ao porto marítimo situado em Barra de Açu (no estado do Rio de Janeiro), uma linha

\footnotetext{
${ }^{3}$ Projeto apoiado pela Federação das Indústrias de Minas Gerais - FIEMG. Ver http://www.institutoestradareal.com.br/
} 
independente de transmissão de energia e uma adutora de água para captação e para o mineroduto.

O mineroduto com extensão de $525 \mathrm{~km}$ é considerado o maior do mundo para minério de ferro. Com investimentos na casa dos US\$ 8,8 bilhões, o empreendimento prevê produzir 26,5 milhões de toneladas de minério ao ano (Barbieri, 2012; Câmara dos Deputados de Minas Gerais).

\subsection{IMPACTOS ECONÔMICOS}

De acordo com Lage e Milone (2001), os impactos econômicos do turismo podem ser classificados em diretos, indiretos e induzidos.

Impactos diretos estão relacionados às mudanças que ocorrem na produção em um determinado setor, como resultado de alterações na demanda final dos produtos. São "representados pelo total de renda criada nos setores turísticos como resultante direta da variação dos gastos com esses produtos" (Lage \& Milone, 2001, p.128).

Os impactos indiretos estão relacionados às mudanças na produção das atividades econômicas que fornecem bens e serviços ao setor de interesse (turismo, no caso em análise) ou aos seus fornecedores.

Por fim, os impactos diretos e indiretos das atividades turísticas vão incrementar a renda dos residentes na forma de salários, distribuição de lucro, juros e alugueis que serão, em parte, gastos em produtos e serviços da economia local e entorno. Este é denominado impacto induzido (Faria, 2012, p.195).

A estimativa destes impactos econômicos pode ser obtida utilizando-se ferramentas como a matriz de insumo produto ou modelos de equilíbrio geral computável (Santos \& Kadota, 2012), que são complexos, exigem uma grande quantidade de informações, mas conseguem estimar os três impactos mencionados. Outra forma de conhecer os impactos, principalmente os diretos, é verificar mudanças em variáveis econômicas chaves, que podem 
sinalizar alterações de tendências no ritmo econômico de uma localidade ou região. É o caso de avaliar alterações na composição setorial de emprego e renda de uma localidade, como também no produto interno bruto (PIB) municipal. Este será o método aqui empregado, onde através de análises do comportamento de variáveis selecionadas, será analisado o impacto dos setores de turismo e mineração na economia de Conceição do Mato Dentro, visando comparar a relevância econômica de ambos em um mesmo território, durante um determinado período de tempo.

Em primeiro lugar, será avaliado o comportamento do PIB municipal, no período de 1999 a 2011. O PIB do município tem no setor serviços seu maior peso e sua maior variação ocorreu no período 2007-2008, período da chegada da mineradora. As entrevistas realizadas com atores locais, especialmente empresariado local e representante da igreja, atestaram que a principal atividade no município é o comércio, e que o turismo tem participação pequena na economia.

No período 2008-2009, início da recessão econômica a nível internacional, o PIB da agropecuária cai, o de serviços não altera, e o da indústria cresce $26 \%$, menos que o ano anterior, o que influenciou no crescimento de $1 \%$ do PIB total.

Sobre a pecuária e a agricultura, possuem pequena participação no PIB municipal, ganhando apenas do setor industrial, confirmando informação colhida durante a entrevista com empresário local e proprietário de pousadas, que afirmou que as atividades agrícolas “eram mínimas antes da mineração”. Por outro lado, o responsável pelo Santuário Diocesano do Senhor Bom Jesus de Matosinhos, em Conceição do Mato Dentro, afirmou que a pecuária e a agricultura de subsistência são as principais fontes de renda para quem reside na zona rural (34\% da população do município, de acordo com o Censo 2010). Percebe-se a queda do setor a partir de 2008. Com a mineração, as pessoas do campo migram para a zona urbana em busca de novas oportunidades de trabalho, como afirmou a secretária de turismo do município. 
Gráfico 01 - Produto Interno Bruto de Conceição do Mato Dentro:1999-2011(Valores Constantes em $\mathrm{R} \$ 1000)$

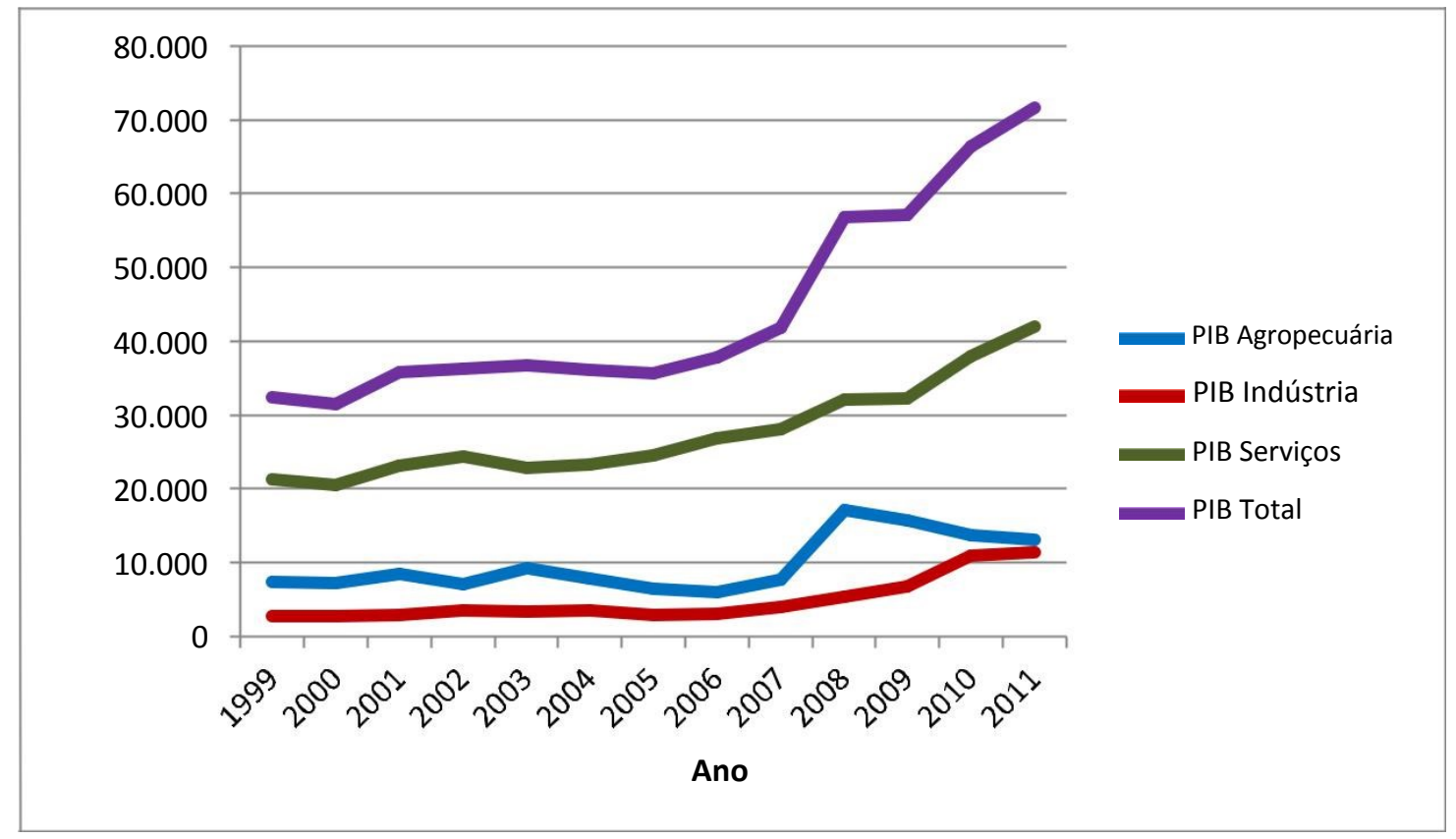

Fonte: Elaboração própria, com base no IBGE

Apesar da participação do PIB da indústria ser a menor no PIB do município, foi o setor que teve maior crescimento, $185 \%$ de incremento no período 2007-2011, enquanto o da agropecuária foi de $70 \%$ e o de serviços $49 \%$, conforme apresentado pelo Gráfico 01 .

No gráfico 02, a seguir, é possível notar o aumento do número de estabelecimentos turísticos devido à alteração na demanda. Primeiramente, observa-se um crescimento, desde o ano de 2002, dos setores de transporte rodoviário, de restaurantes e serviços de alimentação e bebida e, a partir de 2004, do setor de hotéis e similares. Portanto, aumenta-se a renda gerada pelo setor, o que caracteriza o impacto direto do turismo. 
Gráfico 2 - Estabelecimentos Turísticos, em CMD: 2002-2012

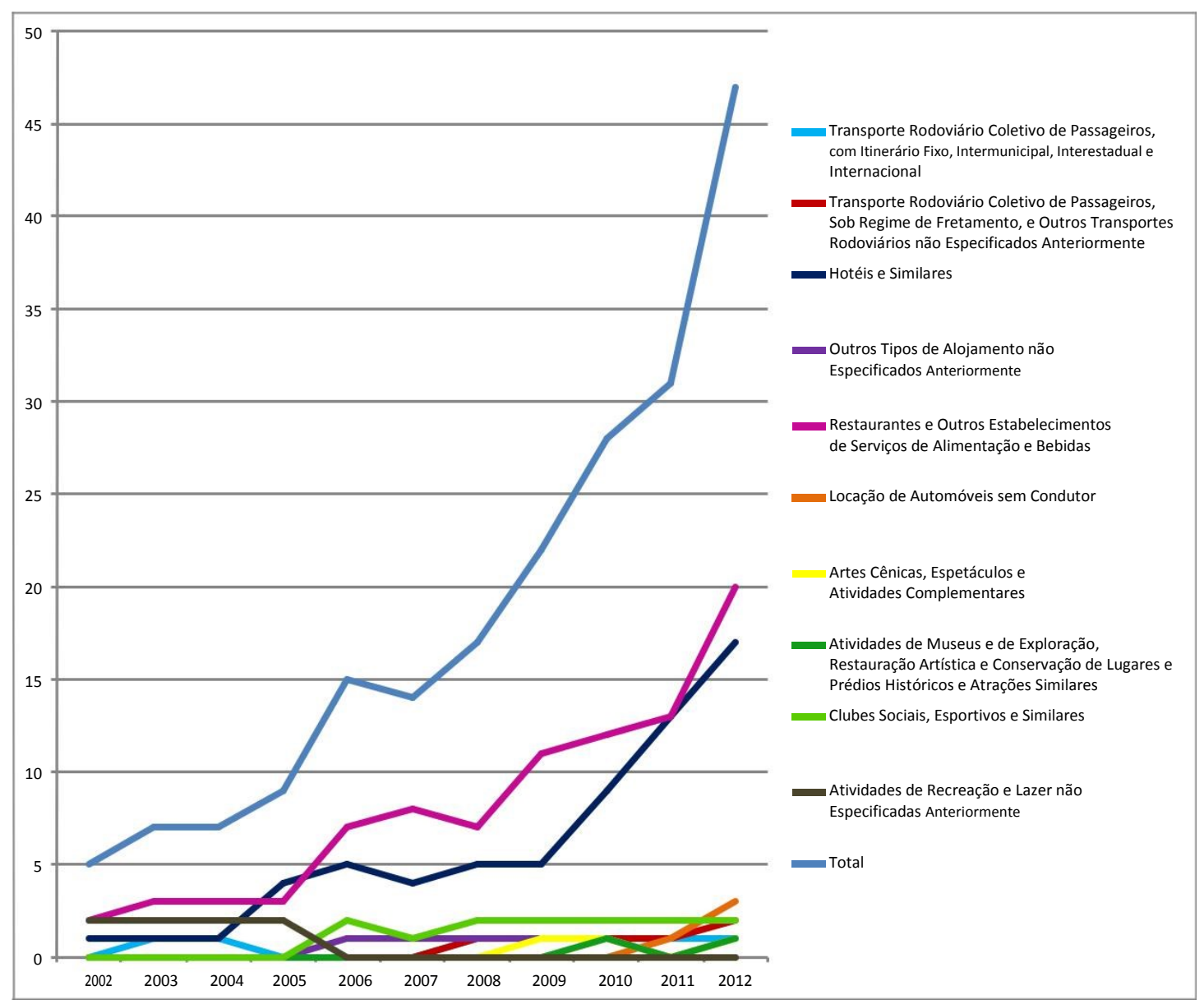

Fonte: Elaboração própria, com base no Ministério do Trabalho e Emprego - RAIS/MTE.

Entretanto, nos defrontamos com uma situação ímpar, pois o impacto em atividades características do turismo foi influenciado também pela atividade mineradora, pois o incremento de trabalhadores devido a mineração na cidade demandou alojamento e utiliza a infraestrutura hoteleira existente, inclusive estimulando a construção de outras mais, como mostra a ascensão da curva deste setor a partir do ano de 2009. Este incremento dos setores turísticos movimenta a cadeia econômica local e regional.

Analisando agora pela ótica do emprego, gráfico 03, pode-se notar que, até 2011, o setor de Serviços era o que mais gerava empregos, sendo ultrapassado no mesmo ano pelo setor de Construção Civil, que registrou crescimentos significativos desde 2007, a partir da construção da infraestrutura necessária ao projeto Minas Rio. Em 2011, todos os setores 
registram aumento no número de empregos. Ambos têm um período de estagnação, de 2008 a 2009, anos em que surge a crise econômica mundial. Após 2010, a indústria e a agropecuária continuam crescendo significativamente. Segundo as entrevistas realizadas, a mineradora Anglo tem incentivado a qualificação de mão de obra local através de cursos, em parceria com o Serviço Nacional de Aprendizagem Industrial [SENAI], e contratado parte desta.

O número de empregos no turismo, a partir de 2010, cresceu, principalmente nos ramos de transporte, hospedagem e alimentação. Acredita-se que o setor se desenvolveu consequente à mineração que, segundo as lideranças entrevistadas, é a responsável pelo dinamismo econômico que se verifica na cidade, gerando um fluxo significativo de pessoas de fora do município. Logo, surge a necessidade de maior prestação de serviços de alimentação e hospedagem, durante a semana, e os de transporte entre a sede do município e os locais de implantação da infraestrutura do projeto.

Apesar de contribuir para o dinamismo econômico e com o aumento do número de empregos, a maior parte da mão de obra utilizada é de fora do município, e o incentivo à qualificação se restringe a atividades de interesse da mineração. Além da superlotação de pousadas e hotéis, devido à hospedagem de funcionários da empresa mineradora, a especulação imobiliária aumentou consideravelmente na cidade. 
Gráfico 03 - Empregos por Grande Setor Econômico em CMD,: 2002-2012

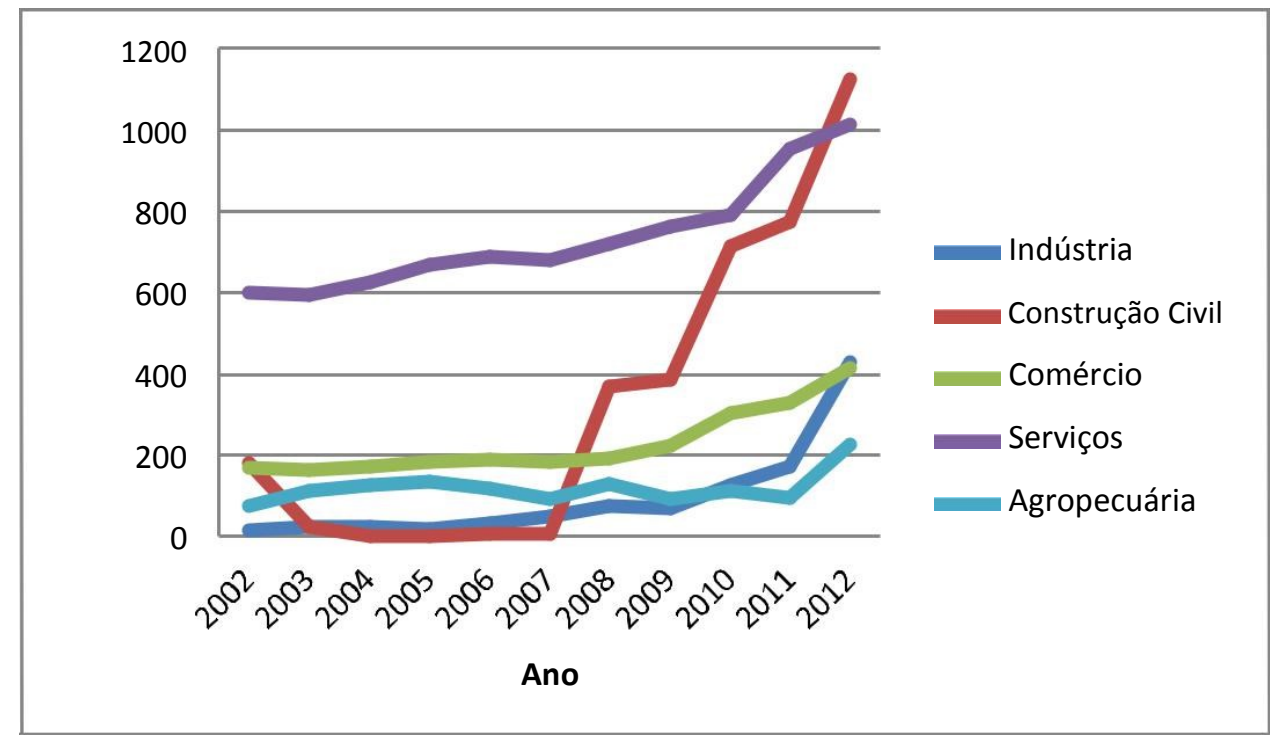

Fonte: Elaboração própria, com base no Ministério do Trabalho e Emprego - RAIS/MTE.

\subsection{IMPACTOS SOCIAIS}

Os impactos sociais do turismo tendem a ser de mais difícil percepção e exigem do analista um olhar cauteloso e profundo. Mesmo planejada e orientada por políticas públicas, a atividade turística pode gerar impactos no modo de vida das comunidades que a recebem. Os indivíduos têm motivações diferentes ao viajar, ao se deslocarem em busca do novo, do surpreendente e ao chegarem ao seu destino suas ações não são as mesmas do cotidiano, afinal ele viaja exatamente para fugir desse cotidiano, assim tem uma rotina diferenciada, está em busca da "liberdade" (Krippendorf, 2001). O turista se apropria de um território para seu lazer que até então tinha outro significado para quem ali vive, causando assim um impacto de estranhamento entre os sujeitos.

Conceição do Mato Dentro recebe anualmente no mês de junho, há mais de duzentos anos, a festa do Jubileu do Bom Jesus do Matozinhos, que atrai romeiros movidos pela fé e devoção de toda a região (Becker, 2009), possuindo um caráter sagrado. Devido às atividades de ecoturismo e mineração no território, nesta festa verifica-se um encontro de pessoas com 
diferentes motivações, do urbano com o rural, da tradição com a modernidade, o que poderíamos chamar de um choque de culturas (Dias, 2003).

Outra categoria de impactos sociais está ligada a relação da estrutura de trabalho, pois o turismo cria "[...] novas oportunidades de renda, novas expectativas e novas oportunidades de trabalho" (Dias, 2003, p.134). A população de Conceição do Mato Dentro que vivia predominantemente da agricultura e do comércio passa a ter no turismo uma nova possibilidade de renda. Muitas pessoas deixam suas terras, ou mesmo as vendem para os "estrangeiros" (no caso, os turistas) para trabalharem com o turismo o que de acordo com Dias (2003) gera "efeitos na estrutural social".

Há impactos nos valores e condutas morais, com aumento da criminalidade e consumo de drogas e álcool nas comunidades receptoras. Esses comportamentos estão presentes em quase todas as sociedades com ou sem turismo (Dias, 2003). Porém o turismo tende a criar condições necessárias para o aumento de determinadas atividades que fogem das regras de conduta moral de determinada sociedade. A questão do consumo de álcool, por exemplo, no distrito de Tabuleiro é levantado por Kutchenski (2006) que o coloca como controverso no distrito já que "[...] supõe-se que o consumo de bebidas alcoólicas entre os habitantes tradicionais seja alta, baseando-se na frequência com a qual se veem bêbados perambulado pelas ruas" (Kutchenski, 2006, p. 152).

Entretanto, devem-se contextualizar estes impactos vis a vis aqueles trazidos pela mineração. O impacto social causado por projetos de exploração de recursos pode ser percebido de formas diferentes, e entre os mais importantes destaca-se a maneira como os benefícios oriundos da utilização dos recursos são distribuídos. Não é comum que as empresas consigam converter os recursos naturais em recursos financeiros, desenvolvendo as capacidades sociais e levando desenvolvimento humano para os locais que se instalam (Franks, 2012). Grupos sociais mais vulneráveis, como as comunidades atingidas pelo Projeto Minas Rio, tendem a sofrer mais com os impactos sociais (Pereira, Becker \& Wildhagen, 2013). 
Dentre os impactos negativos estão os relacionados com o meio ambiente, como a redução de cursos d'água, extinção de nascentes, alteração do uso da terra em grande escala para implementação da barragem de rejeitos, mudança no perfil do relevo da região. Estes e outros impactos devido ao projeto Minas Rio estão devidamente listados no Parecer Único do SISEMA N01/2008 (Minas Gerais, 2008).

Os impactos sociais também são numerosos, desde a retirada de famílias das suas terras até problemas relacionados à segurança pública, saúde, aumento populacional, expansão urbana entre outros. De acordo com o estudo de Impacto Socioambiental (Diversus, 2011), cerca de 1.500 pessoas foram diretamente atingidas pelas obras do empreendimento Minas-Rio, um grande número delas localizadas nos distritos de Córregos e São Sebastião do Bom Sucesso. Ainda de acordo com o estudo, a maioria das pessoas é constituída por jovens, na faixa etária de 10 a 19 anos.

Durante todo o processo de licenciamento do projeto Minas-Rio, várias violações de direitos das comunidades atingidas ocorreram e inúmeras denúncias de problemas ambientais foram realizadas 4 . Dentre os impactos relatados por quem foi e ainda é atingido pelo empreendimento através de diversas denúncias ao Ministério Público Estadual está o não reconhecimento dos atingidos, problemas com regularização fundiária, destruição dos modos de vida local e degradação dos cursos d'água (Pereira, Becker \& Wildhagen, 2013).

Enormes mudanças acontecem no território quando se trata de algum tipo de exploração, a terra que muitas vezes era percebida pelo seu valor de uso passa a ter um valor de troca. Entendendo, conforme Harvey (2010), a terra como uma mercadoria que pode satisfazer uma necessidade humana, ela servia para as comunidades atingidas pelo projeto Minas-Rio como forma de subsistência. A partir do momento em que a terra passa a se tornar uma mercadoria, passa a ter outra utilidade, agora para a extração mineral.

O empreendimento Minas Rio chegou a Conceição do Mato Dentro gerando muita expectativa do ponto de vista econômico, foi visto como uma grande oportunidade de

4 Como mostrado em uma séria de reportagens veiculadas, no mês de abril de 2014, pelo Jornal O Tempo intitulado "Um mineroduto que passou em minha vida" e por denúncias de exploração de trabalhadores quando a empresa foi autuada junto com outras três prestadora de serviço pelo Ministério do Trabalho e Emprego, alegando trabalho análogo à escravidão. Ver Pedrosa \& Ariadne, 2014. 
dinamização da economia local. A possibilidade do aumento da oferta de emprego atraiu um grande número de "forasteiros", pessoas que não eram da cidade, já que não houve tempo de uma capacitação e formação profissional da mão de obra local, causando uma migração de trabalhadores que a cidade não estava preparada para receber, sobrecarregando os sistemas de saúde, habitação e segurança pública. Ainda houve uma migração do campo para a sede do município, buscando oportunidades na cidade.

De acordo com o Departamento de Assistência Social da Secretária de Desenvolvimento Humano de Conceição do Mato Dentro, houve aumento do consumo de álcool e drogas, do desemprego e da prostituição na cidade. Além de um crescimento urbano desordenado que foge às regras municipais de uso e ocupação do solo. Existe um grande número de moradias precárias e ocupações irregulares, muitas delas de pessoas que deixaram o campo em busca das supostas oportunidades da mineração ou até mesmo as que foram expulsas de suas terras por ela.

\section{ANÁLISE DA DISTRIBUIÇÃO DE RENDA NO MUNÍCIPIO}

Para investigar a distribuição de renda consultaram-se vários indicadores, conforme apresentado na Tabela 1. Verifica-se que a renda per capita da população de CMD, no período analisado, acompanhou a tendência brasileira, embora a renda dos moradores de CMD, em termos relativos, tenha aumentado mais que a do Brasil, no período analisado. 
Tabela 1 - Renda, Pobreza e Desigualdade em Conceição do Mato Dentro e Brasil: 1991-2010

\begin{tabular}{|c|c|c|c|c|c|c|}
\hline \multicolumn{7}{|c|}{ Renda, Pobreza e Desigualdade } \\
\hline \multicolumn{4}{|c|}{ Conceição do Mato Dentro - MG } & \multicolumn{3}{|c|}{ BRASIL } \\
\hline Indicadores & 1991 & 2000 & 2010 & 1991 & 2000 & 2010 \\
\hline Renda per capita(R\$) & 159,2 & 220,9 & 384,4 & 447,5 & 592,4 & 793,8 \\
\hline$\%$ extremamente pobres & 43,3 & $32, \$$ & 9,23 & $18, \phi$ & 12,4 & 6,6 \\
\hline$\%$ pobres & $69, \phi$ & 58,7 & 25,1 & 38,1 & 27,9 & 15,2 \\
\hline Índice de Gini & 0,57 & 0,63 & 0,49 & 0,63 & 0,64 & $\overline{0,60}$ \\
\hline
\end{tabular}

Fonte: PNUD, Atlas do Desenvolvimento Humano, 2013.

A porcentagem de extremamente pobres 5 apresentou uma redução, saindo dos 43,3\%, em 1991, para 9,2\% em 2010, uma queda mais significativa do que a verificada para o Brasil. A participação dos pobres também cai no período analisado, com queda mais acentuada em CMD. Entretanto, em 2010, no tocante a representação dos pobres na população, os índices de CMD ainda eram maiores que do Brasil (25,1\% para CMD em comparação a $15,2 \%$ no Brasil). Este fato revela a concentração de renda no município, demonstrada pelo Índice de Gini $^{6}$ que, de 0,57 , em 1991, incrementa para 0,63, no ano 2000, e cai para 0,49 no ano de 2010. Vale destacar que, no ano de 2000, este índice para CMD e para o Brasil eram similares. Entretanto, em 2010, CMD avança mais na redução da desigualdade em comparação ao Brasil.

Observa-se uma tendência de melhora nos indicadores de desigualdade a partir dos anos 2000, que pode ser melhor visualizado pela Tabela 2, onde os estratos de menor renda passam a se apropriar de maior parcela da renda municipal, embora os $20 \%$ mais ricos ainda concentrem mais de $50 \%$ da renda do município.

\footnotetext{
${ }^{5}$ Para o Instituto de Pesquisa Econômica Aplicada (IPEA, 2012), a pobreza extrema é quando a renda per capita fica inferior a $1 \frac{1}{4}$ de salário mínimo, e esta é a linha de pobreza utilizada na Tabela 02.

${ }^{6}$ Este índice situa-se entre 0 e 1 , sendo que zero corresponde a completa igualdade de renda entre as pessoas de um grupo em análise e 1 corresponde a completa desigualdade (IPEA, 2004).
} 
Tabela 2- Apropriação de Renda no Município de CMD: 1991-2010

\begin{tabular}{|c|r|r|r|}
\hline \multicolumn{4}{|l|}{ Porcentagem da Renda Apropriada por Estratos da População } \\
\hline Conceição do Mato Dentro - MG \\
\hline Estratos da População/Ano & 1991 & \multicolumn{1}{l|}{2000} & \multicolumn{1}{c|}{2010} \\
\hline $20 \%$ mais pobres & 3,49 & 1,87 & 3,73 \\
\hline $40 \%$ mais pobres & 9,99 & 7,59 & 12,06 \\
\hline $60 \%$ mais pobres & 20,4 & 16,7 & 25,39 \\
\hline $80 \%$ mais pobres & 37,94 & 33,92 & 47,33 \\
\hline $20 \%$ mais ricos & $62,0 \varnothing$ & $66,0 \$$ & 52,67 \\
\hline
\end{tabular}

Fonte: PNUD, Atlas do Desenvolvimento Humano, 2013.

O turismo como atividade econômica pode provocar um impacto direto com relação à renda nos territórios no qual se insere, de acordo com a forma como ele se desenvolve pode atenuar ou acentuar a pobreza (Faria, 2012a). No caso de Conceição do Mato Dentro, de acordo com a Tabela 02, houve uma clara redução nos percentuais de pobres e de extremamente pobres entre os anos de 2000 e 2010, mas não há indícios concretos da contribuição do turismo para essa redução. Os indicadores sinalizam uma dinâmica econômica local, no período analisado, cujo carro chefe foi o setor de mineração.

\section{CENÁRIOS POSSÍVEIS}

A partir do momento em que duas atividades distintas fazem uso dos recursos naturais no território de Conceição do Mato Dentro, surge o grande desafio de concilia-las. Por um lado a degradação do território pela extração de minério de ferro em grande escala, por outro um uso turístico que pode ser menos agressivo do ponto de vista socioambiental.

O turismo ainda necessita encontrar um ponto de equilíbrio entre sua atividade e a exploração dos recursos naturais. A mineração, por sua vez, é tida como uma das atividades responsáveis pela degradação ambiental, apesar de ser importante e necessária do ponto de vista econômico. 
O turismo e a mineração em um mesmo território não devem ser excludentes. Pensar em soluções que permitam a atuação das duas atividades deve ser uma preocupação constante visando desenvolver alternativas possíveis e criando possibilidades de trabalho e renda complementares à mineração.

Um Plano Regional Estratégico em torno de grandes projetos minerários no Médio Espinhaço foi desenvolvido pelo Centro de Desenvolvimento e Planejamento Regional [Cedeplar/UFMG] (Barbieri, 2014). Neste estudo foram realizadas algumas simulações, utilizando modelos de equilíbrio geral, do impacto econômico local e regional considerando investimentos esperados na área de mineração e receitas derivadas na área do turismo. Os investimentos previstos na mineração referem-se basicamente ao do projeto Minas Rio. No caso do turismo referem-se a uma seleção de projetos para incrementar a infraestrutura turística, formatação de produtos, reforço da comercialização e medidas para fortalecimento institucional e conservação ambiental do município, bem como estimativas de fluxo turístico e receita esperada (Barbieri, 2012). A tabela 3 apresenta as informações utilizadas e resultados encontrados.

Tabela 03-Cenários possíveis em CMD: 2013-2030

Cenários Possíveis nas Atividade de Mineração e Turismo em CMD: 2013-2030

\begin{tabular}{|c|c|c|}
\hline & Mineração & Turismo \\
\hline Investimento (US\$bilhões) & $8, \$$ & 0,05 \\
\hline Receita Esperada (US\$ bilhões) & - & 0,354 \\
\hline Total (US\$ bilhões) & $8, \$$ & 0,404 \\
\hline Resultado esperado período 2013-2030 & & \\
\hline Incremento PIB (variação anual - \%) & 4,64 & 1,26 \\
\hline
\end{tabular}

Fonte: Barbieri, 2014. pgs 31 e 51.

A mineração com investimentos significativos contribui mais para o incremento do PIB de Conceição do Mato Dentro. Mas, vale ressaltar que, com investimentos na atividade turística que representam aproximadamente 5\% do valor da mineração, os resultados sinalizam para um incremento do PIB que corresponde a $27 \%$ do resultado alcançado com a mineração.

A mineração pode deixar um legado importante do ponto de vista da paisagem cultural, entendo-a de acordo com Cosgrove (1989, p.101) "a paisagem como um texto 
cultural", com suas diversas dimensões e possibilidades de leitura. Ações no sentido de recuperar áreas minerárias e lhes atribuir um novo uso podem ser tomadas. Atenta aos problemas trazidos pela mineração e na busca por soluções, no final de 2015, a Câmara Municipal organizou o Seminário "Responsabilidade do Gestor Público na aplicação responsável da CFEM" (Poder Legislativo, 2015), com o propósito de debater com os cidadãos aspectos relevantes da economia mineral para o desenvolvimento do município, especificamente o uso dos recursos provenientes da compensação de extração mineral CFEM. Também foi aprovado pela Câmara Municipal o Orçamento Participativo, de modo que a comunidade possa opinar na gestão dos recursos oriundos do setor mineral.

O território em análise que agora possui a atividade mineral de base exportadora como um setor hegemônico deve criar alternativas para que o turismo, que dava os primeiros passos para se desenvolver, se fortaleça. Ações conjuntas entre o poder público e a sociedade podem criar alternativas viáveis de convivência entre as duas atividades fazendo com que elas não sejam excludentes.

\section{CONSIDERAÇÕES FINAIS}

Conceição do Mato Dentro teve seu surgimento a partir do ciclo do ouro e diamantes, devido a sua localização em um dos caminhos da Estrada Real. Após a exaustão deste ciclo econômico, voltou-se para as atividades agropecuárias e de serviços. Com a política pública de regionalização do turismo se deparou com possibilidades oriundas do ecoturismo. $\mathrm{O}$ turismo encontrou território fértil para exploração dos recursos naturais e culturais e foi aos poucos sendo visto como possível fator de desenvolvimento regional e se iniciaram ações para sua implementação. Entretanto, no decorrer desse processo um novo ciclo de mineração se estabelece no território, a partir da exploração de minério de ferro.

Os indicadores econômicos do comportamento do PIB, número de estabelecimentos das atividades características do turismo e empregos gerados revelam que o dinamismo na 
economia local é decorrente da atividade minerária. A atividade turística estava em processo de consolidação quando os projetos minerários chegaram ao município e outras prioridades são estabelecidas. A estrutura de alojamento e o setor de restaurantes são absorvidos pela mineração para atender a seu expressivo contingente de trabalhadores.

Até o presente momento, o que se verifica é um rápido crescimento econômico local, liderado pelo setor da mineração, com uma redução do número de pobres e aumento da apropriação da renda municipal por estes, embora os $20 \%$ mais ricos ainda concentrem mais de $50 \%$ da renda do município. Constata-se um avanço em termos de desenvolvimento econômico, uma redução da desigualdade social e crescimento da economia. Entretanto, o anseio pelo desenvolvimento humano ainda é um desafio. Observam-se algumas propostas que caminham nesta direção, como a possibilidade de uso dos recursos do CFEM a favor de projetos sociais, mas há ainda muito que trilhar, especificamente quanto a redução de desigualdades sociais, em um território com expressiva concentração de renda como é Conceição do Mato Dentro. Por sua vez, o turismo pode se constituir em uma alternativa econômica para a população e merece ser incentivado.

Os conflitos entre o turismo e a mineração existem e principalmente, a partir de um olhar superficial, podem se revelar de difícil solução, pois fazem uso de um mesmo território para fins distintos, mesmo que ambos aspirem o desenvolvimento da região. Porém o exercício de pensar em soluções e em uma possível convivência deve ser permanente. O olhar deve ser profundo, intenso, inquieto e capaz de criar alternativas criativas e inovadoras acerca das duas atividades. O conflito está em qual tipo de desenvolvimento e a que custo ambiental e social será levado para a região.

É fundamental o envolvimento dos sujeitos do lugar e do poder público implantando políticas e ações que tenham como objetivo ordenar o processo de rápido crescimento econômico pelo qual passa o território, para mitigar os impactos sociais e ambientais dele decorrente, mediar os conflitos e expandir as oportunidades aos menos favorecidos. A oportunidade que ora se apresenta é a criação de estratégias para atingir o objetivo primordial de promover o desenvolvimento humano, ampliar as capacidades dos cidadãos envolvidos em busca de justiça social e maior responsabilidade com o meio ambiente. Estudos realizados 
pelo Cedeplar/UFMG mostram a importância da atividade turística no crescimento do PIB a longo prazo e deveriam ser incentivados, pois a mineração e o turismo podem atuar conjuntamente para o desenvolvimento econômico e social de CMD.

\section{REFERÊNCIAS}

Barbieri, A.F.(Coord). (2014). Plano regional estratégico em torno de grandes projetos minerários no Médio Espinhaço. Belo Horizonte: Secretaria de Estado de Desenvolvimento Regional, Política Urbana e Gestão Metropolitana; UFMG/Cedeplar.

Barbieri, A.F.(Coord.). (2012). Plano regional estratégico em torno de grandes projetos minerários no Médio Espinhaço. Produto 4, lote 1. Belo Horizonte: UFMG/Cedeplar.

Becker, L. C. (2009). Tradição e modernidade: o desafio da sustentabilidade do desenvolvimento na Estrada Real. Tese de Doutorado, Instituto Universitário de Pesquisas do Rio de Janeiro, Rio de Janeiro, RJ, Brasil.

Câmara dos Deputados de Minas Gerais. (s/d). Recuperado em 23 de fevereiro, 2016, de http://www2.camara.leg.br/a-camara/conheca/camara-destaca/mineracao/conceicao-do-matodentro-impacto-socioambiental-preocupa-moradores-e-autoridades

Cosgrove, D. (1989). Geography is everywhere: Culture and symbolism in human landscape. In: D. Gregory e R. Walford. Horizon Human Geography. (O. B. L., Silva, Trad.).Londres: Macmillan. (pp.118-135).

Costa, A. G. (2009). As Estradas Reais para Minas Gerais na Cartografia Histórica do Brasil. In G. D. Calaes \& G. E. Ferreira (Ed.). A Estrada Real e a Transferência da Corte Portuguesa: Programa Rummys - Projeto Estrada Real. Rio de Janeiro: CETEM / MCT / $\mathrm{CNPq} /$ Cyted.

Dias, R. (2003). Sociologia do Turismo. São Paulo: Editora Atlas S.A.

Diversus. (2011). Diagnóstico Socioeconômico da Área Diretamente Afetada e da Área de Influência Direta do empreendimento Anglo Ferrous Minas-Rio Mineração S.A. (Ex-MMX Minas-Rio Mineração S.A.) - Lavra a Céu Aberto com Tratamento a Úmido Minério de Ferro -Conceição do Mato Dentro, Alvorada de Minas e Dom Joaquim/MG - DNPM No: 830.359/2004 - PA/No. 00472/2007/004/2009 - Classe 06. Belo Horizonte, Agosto de 2011. 
Faria, D. M. C. P. (2012). Análisis de la capacidad del turismo en el desarrollo económico regional: el caso de Inhotim y Brumadinho. Tese de Doutorado, Universidade Federal de Minas Gerais, Belo Horizonte, MG, Brasil. Recuperado 12 de janeiro, 2016, de http://www.bibliotecadigital.ufmg.br/dspace/handle/1843/AMSA-8WTK9U

Faria, D.M.C.P. (2012a). Desarrollo, turismo y pobreza: una mirada crítica. Estudios Turísticos, 192, 71-88.

Franks, D. (2012). Avaliação do impacto social de projectos de exploração de recursos. International Mining for Development Center, Austrália. Recuperado em 09 de novembro, 2013, de http://im4dc.org/wp-content/uploads/2012/01/Social-impact-assessment-of-resourceprojects-Portuguese-version.pdf

Furtado, C. (1984). Cultura e desenvolvimento em época de crise. (2a Ed.) Rio de Janeiro: Paz e Terra.

Harvey, D. (2010). Para entender o capital: Livro I. São Paulo: Boitempo.

Instituto Brasileiro de Geografia e Estatística [IBGE]. (2015). Cidades. Recuperado em 22 de fevereiro, 2016, de

http:/www.cidades.ibge.gov.br/xtras/perfil.php?lang=\&codmun=311750\&search=minasgerais|conceicao-do-mato-dentro

Instituto de Pesquisa Econômica Aplicada [IPEA]. (2004). Desafios do Desenvolvimento. Ano 1. ( $4^{\mathrm{a}}$ Ed.). Recuperado em 22 de fevereiro, 2016, de http://desafios.ipea.gov.br/index.php?option=com_content\&view $=$ article \&id=2048:catid=28 \&Itemid $=23$

Instituto de Pesquisa Econômica Aplicada [IPEA] (2012). Comunicados do IPEA. N.155 2012. Recuperado em 18 de novembro, 2016, de http://www.ipea.gov.br/agencia/images/stories/PDFs/comunicado/120925_comunicadodoipea 155_v5.pdf

Krippendorf, J. (2009). A sociologia do Turismo: Para uma nova compreensão do lazer e das viagens. São Paulo: Aleph.

Kutchenski, M. L. O. (2006). Paisagem e ecoturismo: o caso do distrito de Tabuleiro do Mato Dentro - MG. Dissertação de Mestrado, Universidade de Brasília. DF, Brasil. Recuperado em 08 de maio, 2013, de http://repositorio.unb.br/handle/10482/2233?mode=full

Lage, B. H. G. \& Milone, P. C. (2001). Economia do turismo. São Paulo: Atlas.

Minas Gerais. (2008). Parecer Único SISEMA. n. 001/2008. (Cap. 6) para o Projeto Minas Rio. 
Ministério do Trabalho e Emprego. (2015). RAIS. Recuperado 23 de junho, 2014, de http://bi.mte.gov.br/bgcaged/login.php.

Mota, M.G. \& Braick, P. R. (2002). História das cavernas ao terceiro milênio. São Paulo: Moderna.

Pedrosa, A.P \& Ariadne, Q. (2014). Um Mineroduto que passou em minha vida. Jornal O Tempo. Belo Horizonte. Recuperado em 25 de março, 2014, de http://www.otempo.com.br/cmlink/hotsites/especial-mineroduto/

Pereira, D. C., Becker, L. C. \& Wildhagen, R. O. (2013). Comunidades Atingidas por Mineração e Violação dos Direitos Humanos: Cenários em Conceição do Mato Dentro. Revista Ética e Filosofia Política, 15 (1). Recuperado em 22 de janeiro, 2016, http://www.ufjf.br/eticaefilosofia/files/2009/08/16_1_pereira.pdf

Poder Legislativo. Conceição do Mato Dentro - MG. (2015). Informativo da Câmara no. 42. $1^{\circ} .11$ a $30 / 11 / 2015$.

Programa das Nações Unidas para o Desenvolvimento [PNUD]. (2013). Atlas para o Desenvolvimento Humano do Brasil. Recuperado em 14 de dezembro, 2015, de http://www.atlasbrasil.org.br/2013/

Rostow, W.W. (2010). A decolagem para o crescimento sustentado. En: A.N. Agarwala,\& S.P.,Singh.Orgs.). A economia do subdesenvolvimento. (21a Ed.). Rio de Janeiro: Contraponto.

Santos, G.E.O. \& Kadota, D.K.(2012). Economia do Turismo. São Paulo: Aleph. Sen, A. Desenvolvimento como liberdade. (2000). São Paulo: Companhia das Letras.

Sharpley, R. (2000). Tourism and sustainable development: exploring the theoretical divide. Journal of Sustainable Tourism, 8 (1),.1-19. 